\title{
DNA diagnosis of peritoneal fluid cytology test by $C D O 1$ promoter DNA hypermethylation in gastric cancer
}

\author{
Hideki Ushiku ${ }^{1}$ Keishi Yamashita ${ }^{1} \cdot$ Akira Ema $^{1} \cdot$ Naoko Minatani $^{1}$ • \\ Mariko Kikuchi $^{1} \cdot$ Ken Kojo $^{1} \cdot$ Keigo Yokoi $^{1} \cdot$ Toshimichi Tanaka $^{1}$ • \\ Nobuyuki Nishizawa $^{1} \cdot$ Satoru Ishii $^{1} \cdot$ Kei Hosoda $^{1} \cdot$ Hiromitsu Moriya $^{1} \cdot$ \\ Hiroaki Mieno $^{1} \cdot$ Natsuya Katada $^{1} \cdot$ Shiro Kikuchi $^{1} \cdot$ Hiroshi Katoh $^{1}$. \\ Masahiko Watanabe ${ }^{1}$ (i)
}

Received: 11 December 2016/Accepted: 20 January 2017/Published online: 27 February 2017

(c) The International Gastric Cancer Association and The Japanese Gastric Cancer Association 2017

\begin{abstract}
Background Minimal residual disease of the peritoneum is challenging for early cancer detection in gastric cancer (GC). Utility of PCR amplification of cancer-derived DNA has been considered feasible due to its molecular stability, however such markers have never been available in GC clinics. We recently discovered cancer-specific methylation of $C D O 1$ gene in $\mathrm{GC}$, and investigated the clinical potential to detect the minimal residual disease.

Methods One hundred and two GC patients were investigated for peritoneal fluid cytology test (CY), and detection level of the promoter DNA methylation of $C D O 1$ gene was assessed by quantitative methylation specific PCR (QMSP) in the sediments (DNA CY).

Results (1) CY1 was pathologically confirmed in 8 cases, while DNA CY1 was detected in 18 cases. All 8 CY1 were DNA CY1. (2) DNA CY1 was recognized in 14.3, 25.0, 20.0, and $42.9 \%$, in macroscopic Type II, small type III, large type III, and type IV, respectively, while it was not recognized in Type 0/I/V. (3) DNA CY1 was prognostic relevance in gastric cancer $(p=0.0004)$, and its significance was robust among Type III/IV gastric cancer ( $p=0.006$ for overall survival and $p=0.0006$ for peritoneal recurrence free survival). (4) The peritoneal recurrence was hardly seen in GC patients with potent perioperative chemotherapy among those with DNA CY1. Conclusions DNA CY1 detected by Q-MSP for CDO1 gene promoter DNA methylation has a great potential to
\end{abstract}

Masahiko Watanabe

gekaw@med.kitasato-u.ac.jp

1 Department of Surgery, Kitasato University School of Medicine, Kitasato 1-15-1, Minami-ku, Sagamihara, Kanagawa 252-0374, Japan detect minimal residual disease of the peritoneum in GC clinics as a novel DNA marker.

Keywords Cysteine dioxygenase type $1(\mathrm{CDO} 1) \cdot$ DNA methylation - Gastric cancer - Peritoneal fluid cytology test . DNA diagnosis

\section{Introduction}

Gastric cancer is the fifth most common malignancy (952,000 cases in 2012) and the third leading cause of cancer-related death $(723,000$ deaths in 2012) worldwide [1]. Advanced gastric cancer defined as pT2 or beyond still remains poor survival outcomes despite progress in multidisciplinary therapy [2-6], while early gastric cancer is largely a curable disease $[3,4,7]$.

Among advanced gastric cancer, tumors with macroscopic features of type III and type IV exhibited dismal prognosis as compared to those with type I/II/V tumors predominantly due to peritoneal recurrence including microscopic tumor dissemination representing positive peritoneal cytology test (CY1) [5, 6, 8]. CY1 was recently acknowledged as stage IV factor from a prognostic point of view in both the eastern countries [9-12] and the western countries [13, 14].

Despite pathological CY0 confirmation after curative surgery, many tumors with macroscopic features of type III and type IV encountered peritoneal recurrence [5, 6], suggesting that pathological CY0 is not sufficient to guarantee microscopic tumor free status. In fact, mRNA derived from the tumor cells was actually detected by sensitive PCR test using CEA mRNA, a specific marker for the epithelium-derived cells, even though pathological CY0 was confirmed, and such tumors (CEA mRNA 
positive tumors) showed dismal prognosis [15]. However, mRNA is fragile, and clinical test using mRNA may not be stable as a clinical test and seems to have an obstacle for general prevalence. That is why DNA marker representing cancer detection has been highly wanted due to its extraordinarily stable features of DNA. It has a great potential for general prevalence, once it has been got.

Promoter DNA methylation has such an excellent potential, if frequency in primary cancer tissues is high, but such frequent methylation gene is precious [16-19]. Rigorous explorative studies searching for such tumor specific and frequent DNA methylation finally reached CDOl gene as an ideal DNA marker representing cancer detection [20]. CDOI DNA methylation has been recently confirmed as a cancer detection tool in liquid biopsy such as bile [10] or plasma [21] as well as the primary tumor tissues [22-26]. In this study, we for the first time investigated a clinical potential of $C D O 1$ DNA methylation to detect minimal residual disease of gastric cancer.

\section{Methods}

\section{Patients}

Between 2009 and 2012, a total of 102 patients with histologically confirmed primary gastric cancer underwent surgery at the Department of Surgery, Kitasato University School of Medicine, Sagamihara, Japan. During this term, we principally performed peritoneal lavage cytology test for gastric cancer with cT2 or beyond, while it was basically omitted for $\mathrm{cT} 1$ gastric cancer.

This study was conducted in accordance with the Declaration of Helsinki and was approved by the Research Ethics Committee of Kitasato University School of Medicine. Informed consent was obtained to use peritoneal fluids.

\section{Clinicopathological factors}

We performed prognostic analysis to identify independent prognostic factors in the 102 gastric cancer patients who underwent gastrectomy. Pathological tumor depth $(\mathrm{pT})$ and pathological lymph-node metastasis $(\mathrm{pN})$ were classified according to the Japanese Classification of Gastric Cancer staging system, 14th edition [27]. The results of cytological examinations of either ascites or peritoneal lavage fluid (CY cytology test) were evaluated according to the Japanese Classification of Gastric Cancer Association (JGCA) and were classified as CY1 (positive cytology test), CY0 (negative cytology test), CYX (not assessed by cytology test).
Other clinico-pathological factors included age, gender, macroscopic feature, surgical approach (open versus laparoscopic method), surgical procedures (total gastrectomy-TGR, distal gastrectomy-DGR, proximal gastrectomy-PGR, and gastrojejunostomy-GJ), lymph node dissection (D0/D1/D1+/D2), operation time (minutes), estimated blood loss ( $\mathrm{ml}$ ), adjuvant chemotherapy, neoadjuvant chemotherapy, lymphatic permeation (ly), vascular permeation (v), pretreatment value of serum CEA, pretreatment value of CA19-9, and cytological diagnosis (CY), and $\mathrm{pT}$ factor, $\mathrm{pN}$ factor, and the 14th JGCA stage. Macroscopic features were based on Barrmann classification (Type I polypoid, Type II Fungating, ulcerated with sharp raised margins, Type III Ulcerated with poorly defined infiltrative margins, Type IV Infiltrative, predominantly intramural lesion, poorly demarcated, Type V Unclassified feature). Representative tumors were shown in Fig. 1a. Patients background was shown in Table 1.

\section{Chemotherapy}

Adjuvant Chemotherapy Trial of S-1 for Gastric Cancer (ACTS-GC) shown in 2007 [2], in that S-1 is effective as adjuvant chemotherapy, and we positively participated in this clinical trial. Since then, patients with stage II/III advanced gastric cancer were recommended to receive adjuvant chemotherapy with S-1. S-1 was also recommended to be received even for gastric cancer patients with CY1 who underwent gastrectomy since then. The Institutional Review Board of the Kitasato University Hospital approved the use of Docetaxel/Cisplatin/S1 (DCS) regimen for the management of far advanced gastric cancer since 2009 [28].

\section{DNA extraction and bisulfite modification}

For cytology test, $200 \mathrm{ml}$ normal saline was put into the upper abdominal cavity, and $50 \mathrm{ml}$ peritoneal washing fluids were collected for cytology test and DNA cytology test, respectively. Genomic DNA from the primary gastric cancer tissue species and 102 peritoneal cytology sediments after $5 \mathrm{~min}$ centrifugation $(1 \times 1500 \mathrm{rpm})$ was extracted using QIAamp DNA Mini Kit (QIAGEN Sciences, Hilden, German). Bisulfite treatment was done by using an EZ DNA Methylation-Gold ${ }^{\mathrm{TM}}$ Kit (Zymo Research, CA, Orange, USA) and the bisulfite-treated DNA was applied to polymerase chain reaction (PCR).

\section{Quantitative TaqMan methylation-specific PCR (Q-MSP)}

Quantitative TaqMan methylation-specific PCR (Q-MSP) was carried out using iQ Supermix (Bio-Rad, Hercules, 

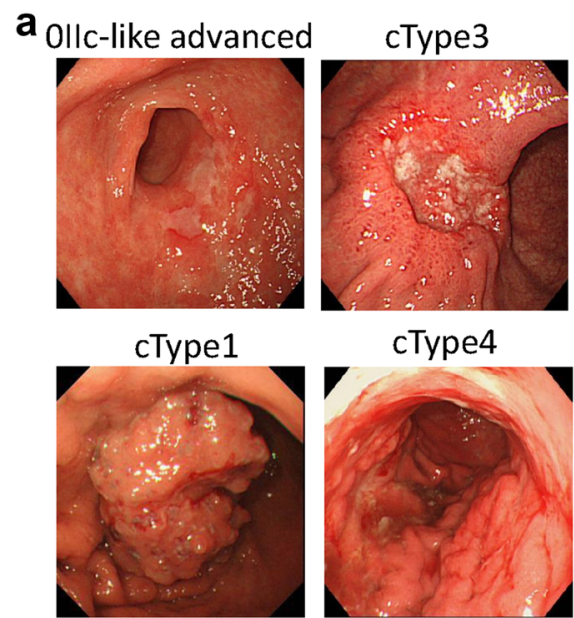

cType4

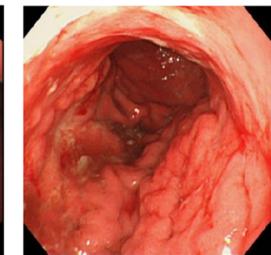

cType2

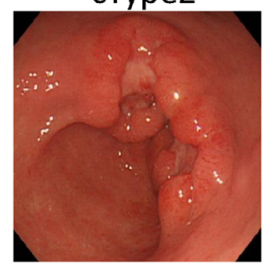

cType5

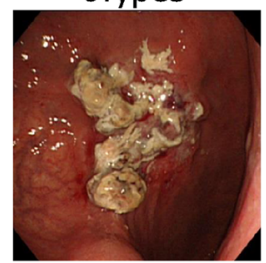

b

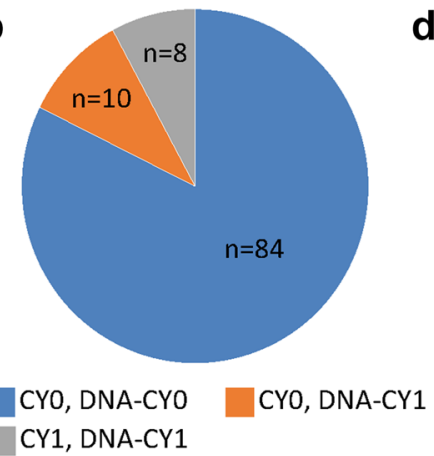

C $(\%)$

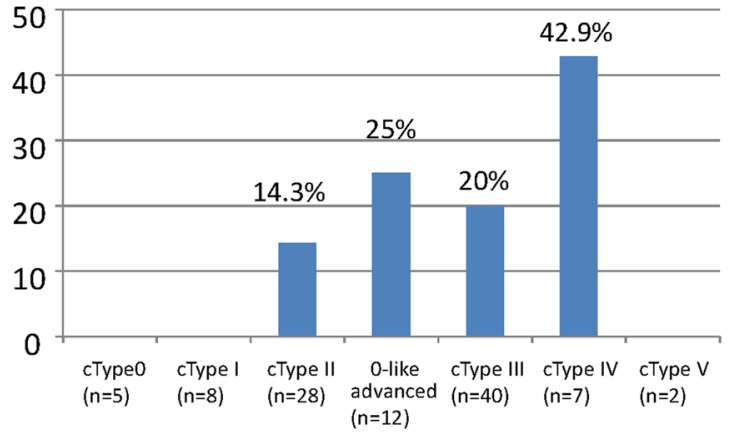

Fig. 1 Representative image findings of upper gastrointestinal scope of gastric cancer and DNA CY status. a Macroscopic features were based on Barrmann classification. Image findings of OIIc-like advanced tumor (defines as small Type III, left-upper panel), cType I (left-middle panel), cType II (left-lower panel), cType III (rightupper panael), cType IV (right-middle panel), and cType V (rightlower panel). b Number distribution of minimally residual diseases defined according to CY1 and DNA CY1 in 102 gastric cancer. c

CA, USA) in triplicate on the iCycler $\mathrm{iQ}^{\mathrm{TM}}$ Real-Time PCR Detection system (Bio-Rad). Primer and probe sequences for TaqMan-MSP are previously described [20, 21]. DLD-1 colon cancer cell line was used as positive control and HepG2 human hepatocellular liver carcinoma cell line as negative control, respectively. The methylation ratio (TaqMan methylation value, TaqMeth $\mathrm{V}$ ) was defined as the quantity of fluorescence intensity derived from promoter amplification of $C D O 1$ gene divided by fluorescence intensity from $\beta$-actin amplification, and multiplied by 100 .

\section{Statistical analysis}

Continuous variables were evaluated by Student's $t$ test; categorical variables were evaluated by Fisher's exact test or the Chi-square test, as appropriate. Survival was calculated by the Kaplan-Meier method. Univariate analyses of prognostic factors for recurrence free survival (RFS) and overall survival (OS) were performed using the log-rank method. OS was defined as time from surgery to death from any causes, and data on surviving patients were censored at the last follow-up. The median follow-up was 50 months

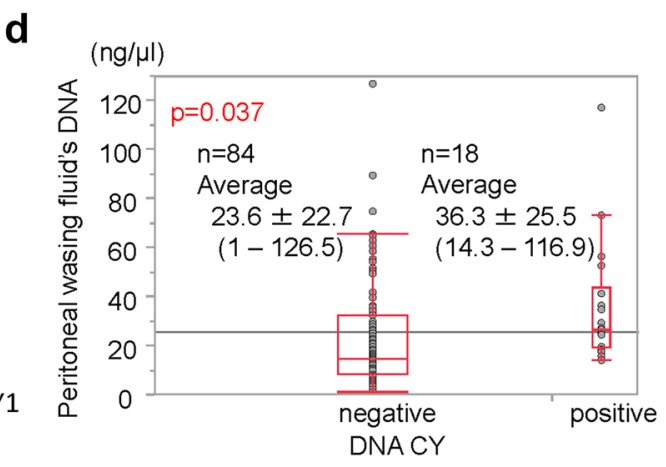

Ratio of DNA CY1 cases in each macroscopic type. DNA CY1 was recognized $14.3 \%$ in cType II, $25.0 \%$ in cType OIIc-like advanced, $20.0 \%$ in cType III and $42.9 \%$ in cType IV. DNA CY1 was not detected in cType 0, cType I and cType V. d The average amount of DNA of peritoneal washing fluids for DNA CY0 and DNA CY1 were $23.6 \pm 22.7$ and $36.3 \pm 25.5 \mathrm{ng} / \mu \mathrm{l}$. The average DNA of DNA CY0 was significantly lower than its average of DNA CY1. $(p=0.037)$

(range 1-69 months). Factors with $p<0.05$ on univariate analysis were subjected to multivariate analysis using a Cox proportional-hazards model to identify independent prognostic factors. All calculations were performed with the use of JMP ${ }^{\circledR} 11$ software (SAS Institute Inc., Cary, NC, USA). $p<0.05$ was considered to indicate statistical significance.

\section{Results}

\section{The amount of DNA in peritoneal washing fluids}

The average amount of DNA in peritoneal washing fluids for DNA CY0 and DNA CY1 were $23.6 \pm 22.7$ and $36.3 \pm 25.5 \mathrm{ng} / \mu \mathrm{l}$. The average DNA of DNA CY0 was significantly lower than its average of DNA CY1. $(p=0.037)$ (Fig. 1d).

\section{Promoter DNA hypermethylation of $\mathrm{CDO1}$ gene in positive and negative control cells}

We recently confirmed degree of promoter hypermethylation by cloned sequence. If we examined methylation level 
Table 1 Clinicopathological characters of gastric cancer

\begin{tabular}{|c|c|c|}
\hline Clinicopathological parameters & Categories & $n=102$ \\
\hline Age & - & $\begin{array}{c}66.2 \pm \\
11.5\end{array}$ \\
\hline \multirow[t]{2}{*}{ Gender } & Male & $78(77 \%)$ \\
\hline & Female & $24(23 \%)$ \\
\hline \multirow{7}{*}{$\begin{array}{l}\text { Macroscopic type (preoperative } \\
\text { diagnosis) }\end{array}$} & 0 & $5(5 \%)$ \\
\hline & 1 & $8(8 \%)$ \\
\hline & 2 & $28(27 \%)$ \\
\hline & 3 & $40(39 \%)$ \\
\hline & $\begin{array}{l}\text { Small } 3 \text { (OIIc-like } \\
\text { advanced) }\end{array}$ & $12(12 \%)$ \\
\hline & 4 & $7(7 \%)$ \\
\hline & 5 & $2(2 \%)$ \\
\hline \multirow[t]{2}{*}{ Surgical approach } & Open & $91(90 \%)$ \\
\hline & Laparoscopic & $11(10 \%)$ \\
\hline \multirow[t]{4}{*}{ Surgical procedures } & TGR & $57(56 \%)$ \\
\hline & DGR & $42(41 \%)$ \\
\hline & PGR & $1(1 \%)$ \\
\hline & GJ & $2(2 \%)$ \\
\hline \multirow[t]{4}{*}{ Lymph node dissection } & D0 (GJ) & $2(2 \%)$ \\
\hline & D1 & $5(4 \%)$ \\
\hline & $\mathrm{D} 1+$ & $26(25 \%)$ \\
\hline & D2 & $69(69 \%)$ \\
\hline Operation time (min) & & $287 \pm 76$ \\
\hline Estimated blood loss (ml) & & $561 \pm 512$ \\
\hline \multirow[t]{2}{*}{ Adjvant chemotherapy } & Yes & $64(62 \%)$ \\
\hline & No & $38(38 \%)$ \\
\hline \multirow[t]{2}{*}{ Neoadjvant chemotherapy } & Yes & $14(13 \%)$ \\
\hline & No & $88(87 \%)$ \\
\hline \multirow[t]{5}{*}{ Lymphatic permeation } & ly0 & $18(17 \%)$ \\
\hline & ly1 & $33(32 \%)$ \\
\hline & ly2 & $26(26 \%)$ \\
\hline & ly3 & $22(22 \%)$ \\
\hline & $\begin{array}{l}\text { no pathological } \\
\text { specimens }\end{array}$ & $3(3 \%)$ \\
\hline \multirow[t]{5}{*}{ Vascular permeation } & v0 & $12(11 \%)$ \\
\hline & $\mathrm{v} 1$ & $27(27 \%)$ \\
\hline & $\mathrm{v} 2$ & $37(36 \%)$ \\
\hline & v3 & $23(23 \%)$ \\
\hline & $\begin{array}{l}\text { no pathological } \\
\text { specimens }\end{array}$ & $3(3 \%)$ \\
\hline \multirow{3}{*}{$\begin{array}{l}\text { Pretreatmental value of serum } \\
\text { CEA }\end{array}$} & positive & $16(15 \%)$ \\
\hline & negative & $84(83 \%)$ \\
\hline & no data & $2(2 \%)$ \\
\hline \multirow{3}{*}{$\begin{array}{l}\text { Pretreatmental value of serum } \\
\text { CA19-9 }\end{array}$} & positive & $14(13 \%)$ \\
\hline & negative & $86(85 \%)$ \\
\hline & no data & $2(2 \%)$ \\
\hline
\end{tabular}

Table 1 continued

\begin{tabular}{|c|c|c|}
\hline Clinicopathological parameters & Categories & $n=102$ \\
\hline \multirow[t]{2}{*}{ Cytological diagnosis } & $\mathrm{CY0}$ & $94(92 \%)$ \\
\hline & CY1 & $8(8 \%)$ \\
\hline \multirow{7}{*}{$\begin{array}{l}\text { JGCA 14th T factor } \\
\text { (pathological) }\end{array}$} & T0 (scar) & $2(2 \%)$ \\
\hline & $\mathrm{T} 1 \mathrm{a}$ & $1(1 \%)$ \\
\hline & $\mathrm{T} 1 \mathrm{~b}$ & $21(20 \%)$ \\
\hline & $\mathrm{T} 2$ & $15(14 \%)$ \\
\hline & $\mathrm{T} 3$ & $23(24 \%)$ \\
\hline & $\mathrm{T} 4 \mathrm{a}$ & $38(37 \%)$ \\
\hline & $\begin{array}{l}\text { no pathological } \\
\text { specimens }\end{array}$ & $2(2 \%)$ \\
\hline \multirow{5}{*}{$\begin{array}{l}\text { JGCA 14th N factor } \\
\text { (pathological) }\end{array}$} & No & $33(32 \%)$ \\
\hline & N1 & $24(23 \%)$ \\
\hline & $\mathrm{N} 2$ & $16(16 \%)$ \\
\hline & N3 & $27(27 \%)$ \\
\hline & $\begin{array}{l}\text { no pathological } \\
\text { specimens }\end{array}$ & $2(2 \%)$ \\
\hline \multirow[t]{9}{*}{ JGCA 14th stage (pathological) } & 0 & $2(2 \%)$ \\
\hline & IA & $16(15 \%)$ \\
\hline & IB & $12(11 \%)$ \\
\hline & IIA & $9(10 \%)$ \\
\hline & IIB & $10(10 \%)$ \\
\hline & IIIA & $29(19 \%)$ \\
\hline & IIIB & $12(11 \%)$ \\
\hline & IIIC & $14(14 \%)$ \\
\hline & IV & $8(8 \%)$ \\
\hline
\end{tabular}

Values are presented as mean \pm standard deviation or number $(\%)$, if not indicated

TGR total gastrectomy, $D G R$ distal gastrectomy, $P G R$ proximal gastrectomy, $G J$ gastrojejunostomy, $C Y$ cytological diagnosis, $J G C A$ Japan Gastric Cancer Association

of DLD1 (methylation positive) and HepG2 (methylation negative) by the cloned sequence, DLD1 cells actually showed methylation in $93 \%$ of the $\mathrm{CpG}$ sites of $\mathrm{CDO1}$ promoter region, and HepG2 cells showed methylation only in $4.7 \%$ of the $\mathrm{CpG}$ sites [21]. We therefore thought that DLD1 and HepG2 cell lines were appropriate for positive and negative control, respectively, for $\mathrm{CDOI}$ methylation analysis.

We then performed Q-MSP for methylated CDOI, by using the same set of both primers and probe which was previously reported [21] after bisulfite DNA treatment, and clearly identified the amplified signals. The DNA template was used in concentration of $200,20,2,0.2,0.02$, $0.002 \mathrm{ng} / \mathrm{PCR}$ reaction, and Q-MSP of the CDO1 clearly detected the methylation within 200-0.2 ng of DNA 
Fig. 2 Methylation specific PCR amplification of $\mathrm{CDO} 1$ and TaqMeth $\mathrm{V}$ in peritoneal lavage cytology of gastric cancer. a $C D O 1$ TaqMeth $\mathrm{V}$ distribution in the peritoneal lavage cytology. Average of CDO1 TaqMeth $\mathrm{V}$ was 0.04 (0-2.24), and the 18 positive cases were detected. Of those, 8 cases were CY1 (red bars) and 10 cases were CY0 (blue bars). b Q-MSP amplification curve of the representative cases

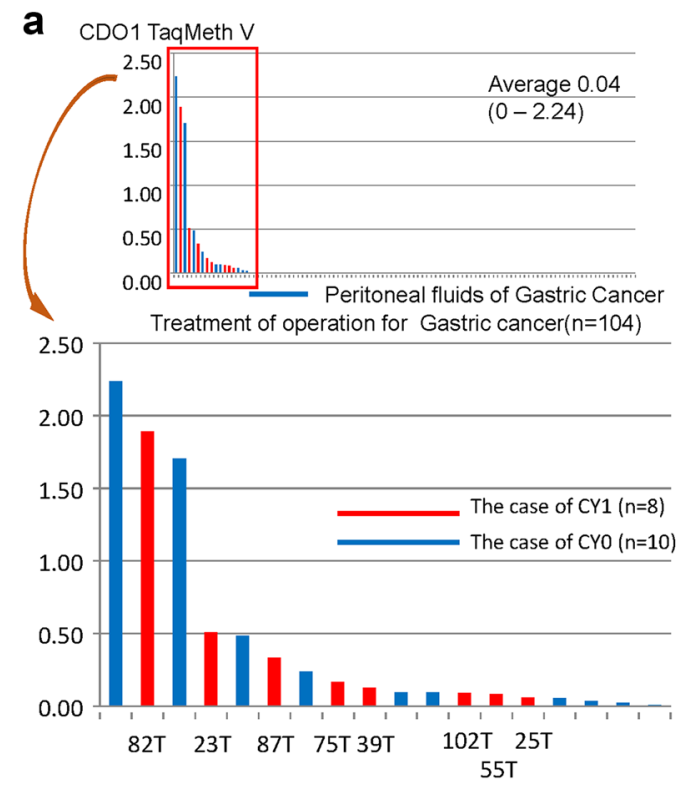

b

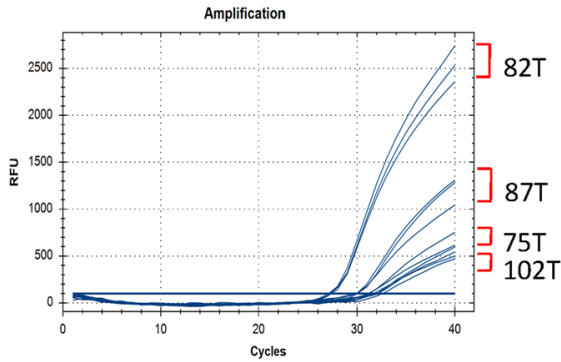

concentration, while it could not detect the methylation in HepG2, the negative control, at all. These findings suggested that even the dense methylation like DLD1 can hardly be detected in a dilution level of about 1000-fold.

\section{DNA diagnosis of peritoneal cytology test (DNA CY test) and CY test in gastric cancer}

Among the 102 gastric cancers, CY1 was routinely and pathologically diagnosed in 8 cases $(7.7 \%)$ by pathologists. DNA diagnosis of peritoneal cytology test (DNA CY test) was assessed by Q-MSP in all the 102 gastric cancer. Among the 102 gastric cancer, DNA CY1 was detected by Q-MSP in 18 cases $(17.6 \%)$. Gastric cancers with CY0 and DNA-CY0 were 84 cases, those with $\mathrm{CY} 0$ and DNA-CY 1 were 10 cases, and those with CY1 and DNA-CY1 was 8 cases (Fig. 1b). TaqMeth values of $C D O 1$ gene in the peritoneal fluids of the 102 gastric cancer was ranged from 0 to 2.2 (average 0.04) (Fig. 2a upper panel), and the 18 positive cases were magnified in the lower panel of Fig. 2a. We showed concrete Q-MSP curves of the representative cases (case, 82, 87, 75, 102) (Fig. 2b), which were corresponded to case numbers in the Fig. 2a. This findings indicated that $\mathrm{CDOl}$ gene methylation is clearly visible for DNA CY1 test, while the value is lower than the primary tumors.

\section{DNA CY1 and clinicopathological factors including prognosis in gastric cancer}

We then investigated the relations of DNA CY1 to clinicopathological factors in gastric cancer (Table 2). DNA CY1 was significantly correlated with the 14th JGCA pathological stage $(p<0.0001)$, but not associated with sex, age, and macroscopic features, where pathological stage was assessed by primary tumor tissues which are sometimes modified by chemotherapy. DNA CY1 was also of prognostic relevance for recurrence free survival (RFS) and overall survival (OS) in 102 gastric cancer. Reflected on patient background, prognosis was poorer in DNA CY1 than in DNA CY0 with regard to RFS $(p=0.005)$ and OS $(p=0.0004)$, respectively (Fig. 3a, b).

DNA CY1 is supposed to be minimal residual disease of the peritoneal dissemination, it may be of clinical significance in gastric cancer with type III and type IV [5, 6]. In our study, the initial recurrent sites were different between localized type (Type I and II) and invasive type (Type III and IV); Type I/II showed 14 recurrences, and peritoneal recurrences were 3 cases, while Type III/IV exhibited 21 recurrences, and included 15 peritoneal recurrences $(p=0.003)$.

\section{Prognostic relevance of DNA CY1 in type III/IV gastric cancer}

We then examined the relations of DNA CY1 to macroscopic features of gastric cancer. Among the 102 gastric cancer, DNA CY1 was detected only in macroscopic type II, III (small/0IIc like advanced, large) and type IV as stated earlier (Fig. 1c). DNA CY1 was recognized in 4 $(14.3 \%)$ out of the 28 type II, in $3(25.0 \%)$ out of the 12 small type III, $8(20.0 \%)$ out of the 40 large type III, and 3 (42.9\%) from the 7 type IV, respectively. On the other hand, DNA CY1 was not detected in macroscopic type 0 , type I, and type V. Moreover, type II gastric cancer with DNA CY1 did not have peritoneal recurrence after S1 adjuvant chemotherapy.

CY1 has been proved to be of prognostic relevance, especially for type III/IV gastric cancer [5, 6], and clinical relevance of DNA CY1 was then focused on type III/IV 
Table 2 Clinicopathological characters of gastric cancer

\begin{tabular}{|c|c|c|c|c|c|}
\hline Clinicopathological parameters & Categories & $n=102$ & DNA CY1 $(n=18)$ & DNA CY0 $(n=84)$ & $p$ value \\
\hline Age & - & $66.2 \pm 11.5$ & $68.4 \pm 10.9$ & $65.7 \pm 11.7$ & 0.37 \\
\hline \multirow[t]{2}{*}{ Gender } & Male & $78(77 \%)$ & 4 & 64 & \multirow[t]{2}{*}{0.89} \\
\hline & Female & $24(23 \%)$ & 14 & 20 & \\
\hline \multirow[t]{6}{*}{ Macroscopic type } & 0 & $5(5 \%)$ & 0 & 5 & \multirow[t]{6}{*}{0.23} \\
\hline & 1 & $8(8 \%)$ & 0 & 8 & \\
\hline & 2 & $28(27 \%)$ & 4 & 24 & \\
\hline & 3 & $52(51 \%)$ & 11 & 41 & \\
\hline & 4 & $7(7 \%)$ & 3 & 4 & \\
\hline & 5 & $2(2 \%)$ & 0 & 2 & \\
\hline \multirow[t]{9}{*}{ JGCA 14th stage (pathological) } & 0 & $2(2 \%)$ & 2 & 0 & \multirow[t]{9}{*}{$<0.0001$} \\
\hline & IA & $16(15 \%)$ & 1 & 15 & \\
\hline & IB & $12(11 \%)$ & 2 & 10 & \\
\hline & IIA & $9(10 \%)$ & 2 & 7 & \\
\hline & IIB & $10(10 \%)$ & 2 & 8 & \\
\hline & IIIA & $29(19 \%)$ & 0 & 19 & \\
\hline & IIIB & $12(11 \%)$ & 0 & 12 & \\
\hline & IIIC & $14(14 \%)$ & 1 & 13 & \\
\hline & IV & $8(8 \%)$ & 8 & 0 & \\
\hline
\end{tabular}

Values are presented as mean \pm standard deviation or number $(\%)$, if not indicated

TGR total gastrectomy, DGR distal gastrectomy, $P G R$ proximal gastrectomy, $G J$ gastrojejunostomy, $C Y$ cytological diagnosis, JGCA Japan Gastric Cancer Association

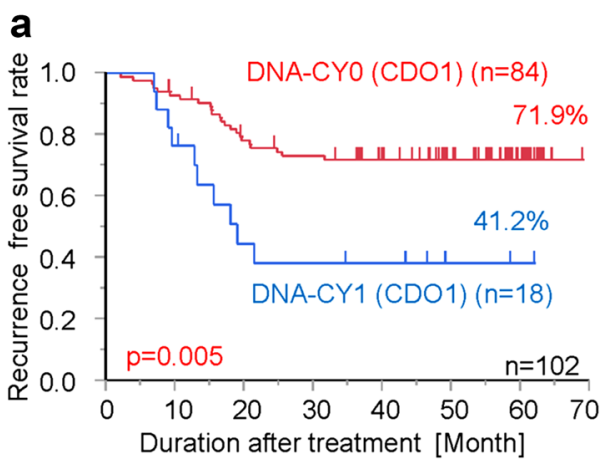

Fig. 3 Prognosis of gastric cancer according to DNA CY status which was determined by quantitative assessment of $C D O 1$ methylation by Q-MSP. a Kaplan-Meier survival curves for RFS were shown, comparing gastric cancer patients with CDO1 TaqMeth V positive (DNA CY1) and those with CDO1 TaqMeth $\mathrm{V}$ negative (DNA

gastric cancer. Among type III/IV gastric cancer, DNA CY1 predicted poorer prognosis for OS as compared to DNA CY0 $(p=0.006)$ (Fig. 4a). More intriguingly, if restricted to peritoneal dissemination with regard to recurrence site, DNA CY1 accurately predict poorer prognosis for peritoneal recurrence free survival than DNA CY0 ( $p=0.0006)$ (Fig. 4b).

As large type III and type IV gastric cancer showed macroscopic high risk for recurrence in gastric cancer, potent preoperative chemotherapy (Docetaxel-containing b

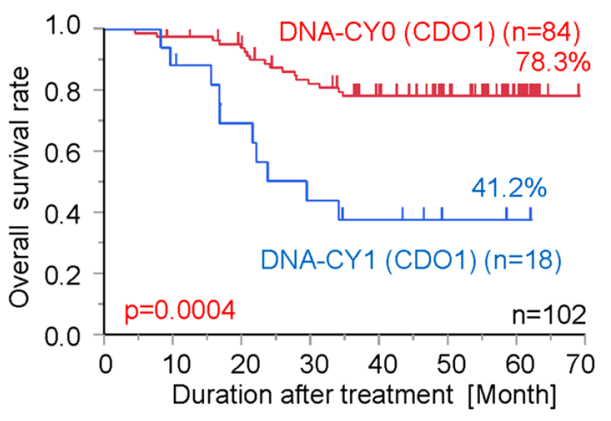

CYO $)(p=0.005)$. b Kaplan-Meier survival curves for OS were shown, comparing gastric cancer patients with $C D O 1$ TaqMeth V positive (DNA CY1) and those with CDO1 TaqMeth V negative (DNA $C Y O)(p=0.0004)$

chemotherapy like DCS regimens) was challenged in combination with postoperative S1 adjuvant chemotherapy. Such multimodality treatments may affect peritoneal recurrence of gastric cancer with DNA CY1. We thus showed the relations of DNA CY1 to peritoneal dissemination and multimodality treatments (Fig. 4c). DCS NAC plus postoperative S1 may be effective with regard to suppression of peritoneal recurrences in case 1, 3, and 13, while postoperative $\mathrm{S} 1$ might be effective in case 7, 11, 15, and 17. 
a Type III/IV gastric cancer

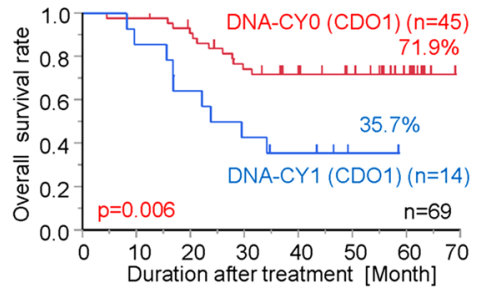

b Peritoneal dissemination recurrence free survival in type III/IV gastric cancer

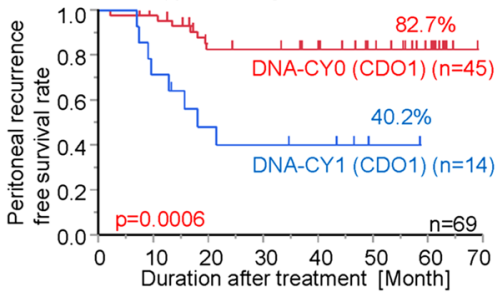

C

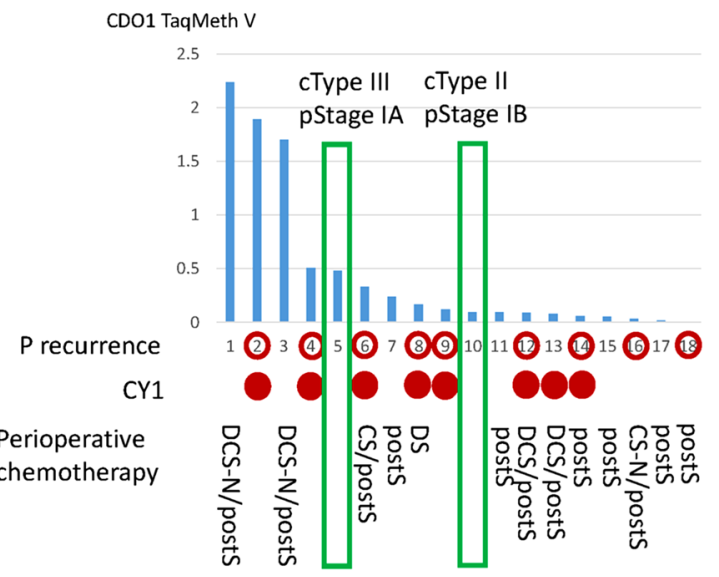

Fig. 4 Prognosis of Type III/IV gastric cancer according to DNA CY status which was determined by quantitative assessment of $C D O 1$ methylation by Q-MSP. a Kaplan-Meier survival curves for OS was made, comparing cType III/IV gastric cancer patients with DNA CY1 and those with DNA CY0 $(p=0.006)$. b Kaplan-Meier survival curves for Peritoneal recurrence free survival was made, comparing cType III/IV gastric cancer patients with DNA CY1 and those with

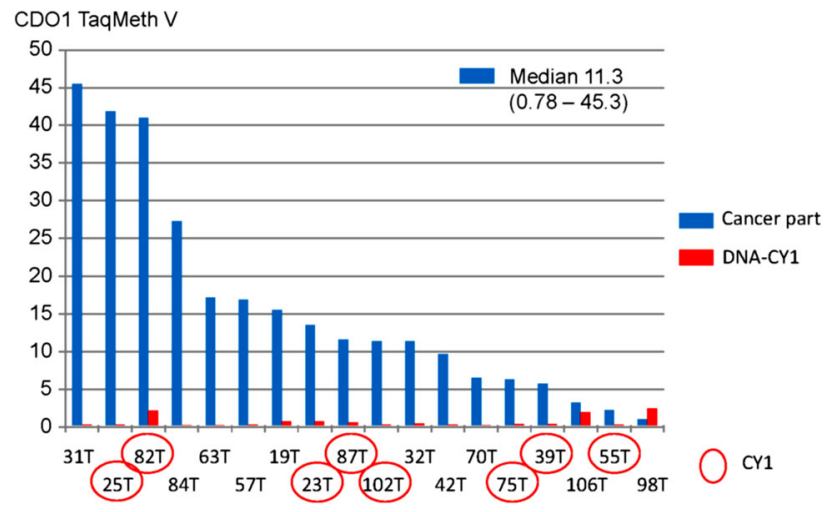

Fig. 5 CDO1 DNA methylation level of peritoneal lavage cytology and the corresponding primary tumors in gastric cancer with DNA CY1. Median CDO1 TaqMeth V was $11.3(0.78-45.3)$ in primary gastric cancer tumors (blue bars)

\section{DNA methylation of the corresponding primary tumors in gastric cancer with DNA CY1}

We then investigated DNA methylation level of the corresponding primary tumors in gastric cancer with DNA CY1 (Fig. 5). As compared to the primary tumors, DNA methylation level of the DNA CY1 is low (1/1000-1/ 20,000). These findings suggested that promoter DNA methylation was recognized in all the primary tumors with DNA CY1.
DNA CY0 $(p=0.0006)$. c DNA CY1 and peritoneal dissemination after multimodality treatments. DCS-N neoadjvant chemotherapy (NAC) of Docetaxel/Cisplatin/S1 regimen, DCS chemotherapy of Docetaxel/Cisplatin/S1 regimen, $C S$ chemotherapy of Cisplatin/S1 regimen, $C S-N$ NAC of Cisplatin/S1 regimen, $D S$ chemotherapy of Docetaxel/S1 regimen, post $S$ adjuvant chemotherapy of S1, $P$ recurrence, peritoneal recurrence

\section{Discussion}

Detection of minimally residual disease of peritoneum is an important challenge in clinical practice of gastric cancer, because such residual tumor cells would recur after macroscopic curative resection of gastric cancer. More importantly, minimally residual tumor cells represented as CY1 may be eradicated by long-term postoperative adjuvant chemotherapy [29]. Minimally residual peritoneal disease representing as CY1 is detected by microscopic cytology test, and it is taken as stage IV in gastric cancer for both the JGCA staging system and UICC or AJCC, because CY1 showed dismal prognosis with peritoneal dissemination similarly with classical stage IV gastric cancer in various countries including Japan [11, 12, 14]. In this current study, we described clinical potential of DNA CY1, assessed by more sensitive test than cytology test, in peritoneal disease of gastric cancer.

This is not the first report describing DNA CY1 in peritoneal disease of gastric cancer. Hiraki et al. recently reported that aberrant gene methylation could be a biomarker for detection of cancer cells in peritoneal wash samples from advanced gastric cancer patients [30]. In this report, they used 6 methylated genes, and methylation of any genes was detected in $75 \%$ of gastric cancer patients with peritoneal disease. In our present study, we used only 1 gene as a biomarker for detection of cancer cells in peritoneal wash samples, and it could detect $100 \%$ of the 
peritoneal disease of gastric cancer. This is due to extraordinarily outstanding features of $\mathrm{CDOl}$ gene with regard to cancer-prone methylation status in human cancer [20].

Among gastric cancer, there are 2 definite phenotypes with regard to recurrent sites. Macroscopic features can affect such different phenotypes; Type I/II showed 14 recurrences, and peritoneal recurrences were 3 cases, while Type III/IV exhibited 21 recurrences, and included 15 peritoneal recurrences $(p=0.003)$ in our study. This difference is interesting, because these macroscopic classification (Type I/II/V vs Type III/IV) could be the most potent independent prognostic factors in gastric cancer [8]. Type IV gastric cancer is undoubtedly characterized by peritoneal disease progression [6], while in type III gastric cancer, CY1 is uniquely the most potent independent prognostic factor [5]. DNA CY1 is surely more frequently recognized in type III/IV than in type I/II/V macroscopic feature. In our present study, there were 4 cases of type II macroscopic feature with DNA CY1, however these cases showed no peritoneal metastasis after postoperative chemotherapy. Peritoneal disease of type I/II/V macroscopic features might be weaker in biological nature in the peritoneum than that of type III/IV macroscopic features. These findings suggested that minimal residual disease may play a prognostic role in cancer progression in type III/IV gastric cancer. Reflected by this finding, DNA CY1 could be prognostic significance in type III/IV gastric cancer (Fig. 4a), reflecting peritoneal recurrence even in the most recent clinical practice of gastric cancer (Fig. 4b).

Peritoneal recurrence is recognized in gastric cancer with CY0, suggesting that CY1 is a test which is not sensitive enough to detect the minimal peritoneal residual disease of gastric cancer. Actually, Kodera et al. previously demonstrated that CEA mRNA detected by PCR is more sensitive than CY1 in gastric cancer, and it actually represented poor prognosis than absence of CEA mRNA [15]. This data suggested that minimally residual cancer cell exists in the peritoneum after curative resection, even if CY0 was confirmed by cytology test. More sensitive method could detect such minimal residual disease. However, mRNA is fragile, and clinical test using mRNA may be instable as a clinical test and seems to have an obstacle for general prevalence. That is why DNA marker representing cancer detection has been highly expected due to its extraordinarily stable features of DNA. But, there have been no report describing cancer-derived DNA detection in the peritoneal disease by the single methylation marker.

CDO1 promoter DNA methylation has been proposed to be a potential candidate of cancer-specific marker in various cancers, and it could be applied to liquid biopsy $[10,21]$. It showed high AUC of ROC curve to discriminate tumor and the corresponding normal tissues in almost solid tumors [20]. In our study, DNA CY1 could be detected more frequently than CY1 in gastric cancer, and it could predict peritoneal recurrence free survival in type III/ IV gastric cancer, which is characterized by peritoneal recurrence among gastric cancer. DNA CY1 could be detected twice as frequently as CY1 in gastric cancer, and it is likely to reflect peritoneal residual disease, because it is significantly associated with peritoneal recurrence free survival.

Intriguingly, all cases with DNA CY1 exhibited promoter DNA methylation in primary advanced gastric cancer (Fig. 5). Minimally residual disease could reflect $\sim 1000$-fold dilution level, however it did not necessarily reflect methylation level of the primary tumors. For example, case 98 showed weak promoter DNA methylation of $\mathrm{CDOl}$ in primary gastric cancer, however it is definitely detected in the peritoneal fluids. In this case, less $C D O 1$ methylation is distributed in primary cancer, while such clone became predominant in the peritoneal fluids. $C D O 1$ is a tumor suppressor activity [20], and $C D O 1$ methylation represents aggressive phenotype of gastric cancer, and such clones is supposed to be disseminated in the peritoneum.

Our study revealed that DNA CY1 could not completely accurately predict peritoneal dissemination, putatively because gastric cancer is treated by multimodality treatments including adjuvant chemotherapy. DCS triplet NAC is a potent neoadjuvant chemotherapy $[28,31]$, and it could often convert CY1-CY0, leading to eradication of the minimal residual disease of gastric cancer. Among our current study cases, 2 cases did not undergo adjuvant chemotherapy after curative surgery, and no recurrences have been detected at present. This 2 cases showed pathological stage IA and IB, and DNA CY1 in such early disease may represent less aggressive phenotype. Both observation term did not reach 5 years, and still needs careful observation.

In conclusion, DNA CY1 detected by Q-MSP for $C D O 1$ gene promoter DNA methylation has a great potential to detect minimal residual disease of the peritoneum in GC clinics as a novel DNA marker.

\section{Compliance with ethical standards}

Conflicts of interest We have no conflicts of interest.

Research involving human participants and/or animals The use of patient's peritoneal washing fluids with gastric cancer are included in this study. This study is conducted in accordance with the Declaration of Helsinki and was approved by the Research Ethics Committee of Kitasato University School of Medicine.

Informed consent Informed consent was obtained to use peritoneal fluids and provided by the space. 


\section{References}

1. International Agency for Research on Cancer WHO (2012) GLOBOCAN 2012: estimated cancer incidence, mortality and prevalence. http://globocan.iarc.fr/Pages/fact_sheets_cancer.aspx. Accessed 27 Feb 2017

2. Sakuramoto S, Sasako M, Yamaguchi T, Kinoshita T, Fujii M, Nashimoto A, et al. ACTS-GC Group, Adjuvant chemotherapy for gastric cancer with S-1, an oral fluoropyrimidine. N Engl J Med. 2007;357:1810-20.

3. Yamashita K, Sakuramoto S, Kikuchi S, Katada N, Kobayashi N, Watanabe M. Validation of staging systems for gastric cancer. Gastric Cancer. 2008;11:111-8.

4. Yamashita K, Sakuramoto S, Nemoto M, Shibata T, Mieno H, Katada N, et al. Trend in gastric cancer: 35 years of surgical experience in Japan. World J Gastroenterol. 2001;17:3390-7.

5. Hosoda K, Yamashita K, Katada N, Moriya H, Mieno H, Sakuramoto $\mathrm{S}$, et al. Preoperative tumor size is a critical prognostic factor for patients with Borrmann type III gastric cancer. Surg Today. 2015;45:68-77.

6. Yamashita K, Hosoda K, Katada N, Moriya H, Mieno H, Higuchi $\mathrm{K}$, et al. Survival outcome of Borrmann type IV gastric cancer potentially improved by multimodality treatment. Anticancer Res. 2015;35:897-906.

7. Yamashita K, Sakuramoto S, Shibata T, Nemoto M, Mieno H, Katada N, et al. Survival outcome of laparoscopic gastrectomy for clinical early (cT1) gastric cancer. Surg Today. 2013;43:1013-8.

8. Yamashita K, Sakuramoto S, Katada N, Kikuchi S, Watanabe M. Simple prognostic indicators using macroscopic features and age in advanced gastric cancer. Hepatogastroenterology. 2014;61:512-7.

9. Association JGC. Japanese classification of gastric carcinoma2nd English edition. Gastric Cancer. 1998;1:10-24.

10. Andresen K, Boberg K, Vedeld HM, Honne H, Jebsen P, Hektoen $\mathrm{M}$, et al. Four DNA methylation biomarkers in biliary brush samples accurately identify the presence of cholangiocarcinoma. Hepatology. 2015;61:1651-9.

11. Fukagawa T, Katai H, Saka M, Morita S, Sasajima Y, Taniguchi $\mathrm{H}$, et al. Significance of lavage cytology in advanced gastric cancer patients. World J Surg. 2010;34:563-8.

12. Lee SD, Ryu KW, Eom BW, Lee JH, Kook MC, Kim YW. Prognostic significance of peritoneal washing cytology in patients with gastric cancer. Br J Surg. 2012;99:397-403.

13. Cancer IUA. TNM classification of malignant tumours. 7th ed. NewYork: Wiley-Blackwell; 2009.

14. Mezhir JJ, Shah MA, Jacks LM, Brennan MF, Coit DG, Strong VE. Positive peritoneal cytology in patients with gastric cancer: natural history and outcome of 291 patients. Ann Surg Oncol. 2010;17:3173-80.

15. Kodera Y, Nakanishi H, Ito S, Yamamura Y, Kanemitsu Y, Shimizu $Y$, et al. Quantitative detection of disseminated free cancer cells in peritoneal washes with real-time reverse transcriptase-polymerase chain reaction: a sensitive predictor of outcome for patients with gastric carcinoma. Ann Surg. 2002;235:499-506.

16. Yamashita K, Upadhyay S, Osada M, Hoque MO, Xiao Y, Mori $\mathrm{M}$, et al. Pharmacologic unmasking of epigenetically silenced tumor suppressor genes in esophageal squamous cell carcinoma. Cancer Cell. 2002;2:485-95.
17. Yamashita K, Park HL, Kim MS, Osada M, Tokumaru Y, Inoue $\mathrm{H}$, et al. PGP9.5 methylation in diffuse-type gastric cancer. Cancer Res. 2006;66:3921-7.

18. Kim MS, Yamashita K, Baek JH, Park HL, Carvalho AL, Osada $\mathrm{M}$, et al. $\mathrm{N}$-methyl-D-aspartate receptor type $2 \mathrm{~B}$ is epigenetically inactivated and exhibits tumor-suppressive activity in human esophageal cancer. Cancer Res. 2006;66:3409-18.

19. Yamashita K, Kim MS, Park HL, Tokumaru Y, Osada M, Inoue $\mathrm{H}$, et al. HOP/OB1/NECC1 promoter DNA is frequently hypermethylated and involved in tumorigenic ability in esophageal squamous cell carcinoma. Mol Cancer Res. 2008;6:31-41.

20. Brait M, Ling S, Nagpal JK, Chang X, Park HL, Lee J, et al. Cysteine dioxygenase 1 is a tumor suppressor gene silenced by promoter methylation in multiple human cancers. PLoS One. 2012;7:e44951.

21. Yamashita K, Waraya M, Kim MS, Sidransky D, Katada N, Sato $\mathrm{T}$, et al. Detection of methylated CDO1 in plasma of colorectal cancer; a PCR study. PLoS One. 2014;9:e113546.

22. Jeschke J, O'Hagan HM, Zhang W, Vatapalli R, Calmon MF, Danilova L, et al. Frequent inactivation of cysteine dioxygenase type 1 contributes to survival of breast cancer cells and resistance to anthracyclines. Clin Cancer Res. 2013;19:3201-11.

23. Wrangle J, Machida EO, Danilova L, Hulbert A, Franco N, Zhang W, et al. Functional identification of cancer-specific methylation of CDO1, HOXA9, and TAC1 for the diagnosis of lung cancer. Clin Cancer Res. 2014;20:1856-64.

24. Vedeld HM, Andresen K, Eilertsen IA, Nesbakken A, Seruca R, Gladhaug IP, et al. The novel colorectal cancer biomarkers CDO1, ZSCAN18 and ZNF331 are frequently methylated across gastrointestinal cancers. Int J Cancer. 2015;136:844-53.

25. Feber A, Arya M, de Winter P, Saqib M, Nigam R, Malone PR, et al. Epigenetics markers of metastasis and HPV-induced tumorigenesis in penile cancer. Clin Cancer Res. 2015;21:1196-206.

26. Deckers IA, Schouten LJ, Van Neste L, van Vlodrop IJ, Soetekouw PM, Baldewijns MM, et al. Promoter methylation of CDO1 identifies clear-cell renal cell cancer patients with poor survival outcome. Clin Cancer Res. 2015;21:3492-500.

27. Association JGC. Japanese classification of gastric carcinoma: 3rd English edition. Gastric Cancer. 2011;14:101-12.

28. Koizumi W, Nakayama N, Tanabe S, Sasaki T, Higuchi K, Nishimura K, et al. A multicenter phase II study of combined chemotherapy with docetaxel, cisplatin, and S-1 in patients with unresectable or recurrent gastric cancer (KDOG 0601). Cancer Chemother Pharmacol. 2012;69:407-13.

29. Yamashita K, Ushiku H, Katada N, Hosoda K, Moriya H, Mieno $\mathrm{H}$, et al. Reduced preoperative serum albumin and absence of peritoneal dissemination may be predictive factors for long-term survival with advanced gastric cancer with positive cytology test. Eur J Surg Oncol. 2015;41:1324-32.

30. Hiraki M, Kitajima Y, Koga Y, Tanaka T, Nakamura J, Hashiguchi $\mathrm{K}$, et al. Aberrant gene methylation is a biomarker for the detection of cancer cells in peritoneal wash samples from advanced gastric cacner patients. Ann Surg Oncol. 2011;18:3013-9.

31. Nakayama N, Koizumi W, Sasaki T, Higuchi K, Tanabe S, Nishimura K, et al. A multicenter, phase I dose-escalating study of docetaxel, cisplatin and S-1 for advanced gastric cancer (KDOG0601). Oncology. 2008;75:1-7. 